\title{
Episodic Abiotic Stress as a Potential Contributing Factor to Onset and Severity of Disease Caused by Phytophthora ramorum in Rhododendron and Viburnum
}

\author{
Tatiana V. Roubtsova and Richard M. Bostock, Department of Plant Pathology, University of California, One \\ Shields Ave., Davis, CA 95616
}

\begin{abstract}
Roubtsova, T. V., and Bostock, R. M. 2009. Episodic abiotic stress as a potential contributing factor to onset and severity of disease caused by Phytophthora ramorum in Rhododendron and Viburnum. Plant Dis. 93:912-918.

Phytophthora ramorum attacks many forest and nursery species, primarily causing trunk or stem cankers, foliar blight, and dieback, and in some species root infection has been demonstrated. However, the abiotic and edaphic factors that influence infection and disease development are unresolved. Root infection by $P$. ramorum and the potential for mild abiotic stress in disease predisposition was examined with Rhododendron hybrid Cunningham's White and Viburnum tinus cv. Spring Bouquet. To impose water stress in a uniform and synchronous manner, osmotic stress induced with $0.2 \mathrm{M} \mathrm{NaCl}$ was selected. Roots were exposed to $\mathrm{NaCl}$ for 16 to $24 \mathrm{~h}$ in modified hydroponic culture or standard potting soil, removed from the $\mathrm{NaCl}$, and then inoculated with zoospores. In the hydroponic regime, disease symptoms developed in Rhododendron and $V$. tinus plants within 1 week after inoculation of salt-stressed roots, whereas symptom development was delayed in nonstressed, inoculated plants. Microscopic examination of roots from both species revealed that their apices were covered with sporangia of P. ramorum. On potted Rhododendron plants inoculated by applying zoospores directly to the soil, stem lesions developed rapidly in salt-stressed plants, with death of the plant occurring within 4 weeks after inoculation. Nonstressed plants survived for 6 to 8 weeks before succumbing to disease, and symptom development in these plants was delayed by 1 to 2 weeks relative to the inoculated, salt-stressed plants. A postinfection episode of salt stress to inoculated roots in the hydroponic regime resulted in significantly faster development of stem lesions in Rhododendron relative to nonstressed, inoculated plants.
\end{abstract}

Sudden oak death (SOD), or ramorum blight, is an emergent disease of mostly woody plants along the Pacific coast of North America (20). The primary species of economic and ecological importance are red oaks (Quercus, section Erythrobalanus), tanoaks (Lithocarpus densiflorus), California bay laurel (Umbellularia californica), and various ornamental and landscape plants such as Rhododendron, Camellia, and Viburnum species. The causal agent initially was isolated from Rhododendron and Viburnum in Europe in 1993 and was characterized as Phytophthora ramorum, a new species, in 2001 (45). In North America, P. ramorum infection of nursery plants has produced immense economic and regulatory consequences (38). Within California ecosystems, this pathogen appears to be most damaging to coast live oak, Quercus agri-

Corresponding author: R. M. Bostock

E-mail: rmbostock@ucdavis.edu

* The $\boldsymbol{e}$-Xtra logo stands for "electronic extra" and indicates that Figure 2 appears in color in the online edition.

Accepted for publication 13 May 2009.

doi:10.1094/PDIS-93-9-0912

(C) 2009 The American Phytopathological Society folia, and tanoak, both of which are keystone species in coastal forests $(11,36,37)$. Lethal girdling cankers can be found near the base of large coast live oak trees, and anywhere on the main bole and branches of tanoaks of any age.

Unlike in many other host species, the $P$. ramorum cankers in live oak and tanoak do not appear to extend below the soil line. Infections of California bay laurel mainly result in nonlethal leaf lesions, which can provide a primary source of inoculum for other species. Here, too, natural infections of $P$. ramorum appear to be largely restricted to the foliage or aboveground portions of the plant. However, in the past several years it has become apparent that root infections occur, as the pathogen can be isolated from roots of naturally infected trees (34) and has been isolated from roots and associated soil from other host species, in some cases with little or no symptom expression $(2,35,40,46)$.

Artificial inoculation of roots of Rhododendron sp. and other species with $P$. ramorum indicates that roots are indeed susceptible and the pathogen moves readily into shoots $(35,39,40)$. Thus, there is strong evidence for the capacity of $P$. ramorum to attack both roots and shoots in some species, but why the propensity for one over the other in a given context is unclear. $P$. ramorum also is reported to cause asymptomatic infections, but how these infections become active is largely speculative (13).

For all plant diseases caused by Phytophthora spp., water status of the host and the environment critically influence disease occurrence and severity $(18,19)$. Water potential influences pathogen behavior and the formation and activity of infective propagules (18). However, water stress and other abiotic factors, including transient episodes of stress such as soil salinity and root anoxia, affect root physiology to directly compromise host resistance, making roots and, in some cases, shoots more vulnerable to disease (7). Cycles of soil moisture extremes dramatically impact the severity of root and crown rot of Rhododendron caused by Phytophthora cryptogea (3), and water stress imposed by deficit irrigation or salinity has a similar effect in a number of other Phytophthora-plant interactions $(4,17,26,27)$.

In light of evidence of a role for root infections in the disease cycle of ramorum blight $(35,40)$, together with the possibility that such infections may remain asymptomatic, a better understanding of specific edaphic and abiotic factors that contribute to the soilborne phase will inform management and risk assessment for this important disease. Such factors may strongly influence the physiology of both host and pathogen, and thus could have a strong effect on inoculum thresholds necessary for infection, the extent and significance of root infection in various hosts (40), the consistency/reliability of pathogenicity tests for the assessment of host range and cultivar resistance, and the efficacy of chemical treatments to manage disease $(25,44)$.

In this study, roots of Rhododendron sp. and Viburnum tinus, two important ornamental hosts that are affected by ramorum blight in nurseries and landscapes, were infected by zoospores of $P$. ramorum, giving rise to running lesions extending into stems and leaves. To determine if an experimentally imposed abiotic stress can enhance disease development caused by $P$. ramorum, we selected brief osmotic stress by exposing roots to $\mathrm{NaCl}$. Salt stress was selected because of the ease of imposing and removing the stress in a uniform and synchronous manner. We examine how osmotic stress to roots prior to inoculation can predispose plants to strongly enhance symptom development caused by $P$. 
ramorum, and discuss this in relation to the potential for abiotic root stress to activate asymptomatic infections. A preliminary report of this work has been published (39).

\section{MATERIALS AND METHODS}

Experimental formats, plants, and stress regimes. Liners of Rhododendron hybrid Cunningham's White and potted plants of $V$. tinus cv. Spring Bouquet were donated by Monrovia Nursery Co. (Azusa, CA) and Hines Nurseries, Inc. (Winters, CA), respectively. Plants were maintained in their original container or transferred to 4-in pots in a temperature-controlled greenhouse until used in experiments. Rhododendrons were maintained in Sunshine Pro Premium potting soil (Sun Gro Horticulture Canada CM Ltd.), and V. tinus plants were maintained in a steamed "UC Mix" type potting soil consisting of equal parts of composted redwood, \#2 washed sand, peat moss, and white pumice, and approximately $1 \mathrm{~kg}$ each of oyster shell calcium and dolomite lime per cubic meter.

Experiments were conducted in two formats: a modified hydroponic culture, and in potted plants in soil. For hydroponic experiments, Rhododendron and V. tinus plants maintained in the greenhouse were removed from their pots and the roots gently rinsed with DI water to remove soil particles. In initial experiments, plants were placed into 200 -ml beakers containing $50 \mathrm{ml}$ of $0.5 \times$ Hoaglands solution for 2 days before exposing them to treatments. The plants were carefully positioned such that only the roots were immersed to minimize contact of the lower stems with the treatment solutions. In later experiments, the stems at the base were wrapped with foam strips to provide a tight seal to support the plants in 50-ml Falcon tubes, with only the roots in contact with the solution. Plants were exposed to the following four treatment regimes: (i) noninoculated; (ii) inoculated; (iii) saltstressed, noninoculated; and (iv) saltstressed, inoculated. Plants in hydroponic culture and selected for salt treatment were transferred to beakers or Falcon tubes to expose the roots to $0.2 \mathrm{M} \mathrm{NaCl} / 0.02 \mathrm{M}$ $\mathrm{CaCl}_{2} / 0.5 \times$ Hoaglands solution $(50 \mathrm{ml})$ for $16 \mathrm{~h}$, rinsed in $0.5 \times$ Hoaglands solution, and then returned to $0.5 \times$ Hoaglands solution. Potted plants were treated with $50 \mathrm{ml}$ of $0.2 \mathrm{M} \mathrm{NaCl} / 0.02 \mathrm{M} \mathrm{CaCl}_{2}$ for $16 \mathrm{~h}$, and then flushed with DI water to reduce the salt in soil solution. Nonstressed controls in both experimental formats were similarly treated, but without $\mathrm{NaCl} / \mathrm{CaCl}_{2}$ in the treatment solutions.

Plants in the hydroponic regime were maintained at room temperature $(25 \pm$ $2{ }^{\circ} \mathrm{C}$ ) under fluorescent lamps in the laboratory. Potted plants were maintained in a controlled access growth chamber at $22^{\circ} \mathrm{C}$ with 12-h day length and $70 \%$ relative humidity under fluorescent and incandescent lights at $150 \mu \mathrm{mol} \mathrm{m} \mathrm{m}^{-2} \mathrm{~s}^{-1}$.

Inoculation and evaluation methods. Two isolates of $P$. ramorum from the UC Davis collection maintained by $\mathrm{D}$. M. Rizzo were used, \#264 isolated from California bay laurel leaves, Marin County, CA, in 2002, and \#397, isolated from Ranunculus spp., Sonoma County, CA, in 2003. These isolates were chosen because both were found to be pathogenic on Rhododendron and $V$. tinus, and both grow and sporulate well in culture.

For the modified hydroponic culture experiments, roots were inoculated by placing them in $0.5 \times$ Hoaglands solution containing zoospore suspensions of $P$. ramorum at a final concentration of $2 \times$ $10^{2}, 2 \times 10^{3}$, or $2 \times 10^{4}$ zoospores $/ \mathrm{ml}$. Potted plants were inoculated by pouring 50 $\mathrm{ml}$ of $0.5 \times$ Hoaglands solution containing $2 \times 10^{3}$ or $2 \times 10^{4}$ zoospores $/ \mathrm{ml}$ at the base of each plant.

Disease was assessed by measuring the length of the lesion along the main stem from the base or soil line and expressed directly as lesion length or as a percentage of the total stem length from the base/soil line of the plant to the tip of the apical meristem. The latter assessment (\% stem lesioned) was determined by digital image analysis of stems with the aid of APS Assess software. Percent stem lesioned was used for some experiments in the final analysis because of slight variation in the size of plants and because some individual plants within a treatment had lesions that involved the entire length of the stem prior to the termination of an experiment (generally 3 weeks after inoculation). Reisolation of the pathogen from the leading margin of the lesion on pimaricin-ampicillinrifampicin-PCNB (PARP) selective medium (22) indicated that this measure provided a good estimate of pathogen colonization and disease. In all initial experiments, the presence of $P$. ramorum was confirmed by its isolation from symptomatic roots, leaves, or stems of inoculated plants on PARP agar and by culture morphology.

Physiological assessment of salt stress. A physiological effect on plants experiencing an episode of salt stress to the roots is a change in the rate of transpirational water loss, which can be measured by the change in weight of the plant over time $(9,42)$. Potted Rhododendron plants were equilibrated to the ambient temperature $(25 \pm$ $2^{\circ} \mathrm{C}$ ) and relative humidity conditions of the laboratory overnight. At approximately $0900 \mathrm{~h}$, the plants were watered with $50 \mathrm{ml}$ of DI water (control) or $50 \mathrm{ml}$ of $0.2 \mathrm{M}$ $\mathrm{NaCl} / 0.02 \mathrm{M} \mathrm{CaCl}_{2}$. The pots were immediately sealed with plastic bags to minimize water evaporation from the soil and roots, leaving the shoots uncovered to allow for transpirational water loss. Plants were weighed every $30 \mathrm{~min}$ for $5 \mathrm{~h}$ and then at 9 and $24 \mathrm{~h}$ from the initiation of the experiment. The difference in weight between first and second measurements (0 and $30 \mathrm{~min}$ ) was used to calculate an initial rate of water loss in $\mathrm{mg} \mathrm{h}^{-1}$. Subsequent measurements determined the loss of weight between each incremental period, and the rate of weight loss $\left(\mathrm{mg} \mathrm{h}^{-1}\right)$ for each time period was expressed as a percentage of the initial rate.

Comparison of abscisic acid (ABA) and salt in predisposition. To see if ABA affected the susceptibility of Rhododendron to $P$. ramorum in hydroponic culture, the following two treatment regimes were added: ABA-treated, inoculated; and ABAtreated, noninoculated. ABA $(( \pm)$-abscisic acid, Sigma \#A1049) was dissolved in a small volume of ethanol, diluted with $0.5 x$ Hoaglands, and added to the root solutions of Rhododendron plants to achieve a final ABA concentration of $10 \mu \mathrm{g} / \mathrm{ml}(32 \mu \mathrm{M})$. This is a concentration within the range reported in previous studies to simulate the predisposing effect of $\mathrm{NaCl}$ on plant roots to infection (6). Plants were inoculated 24 $\mathrm{h}$ later by immersing the roots in a zoospore suspension $\left(2 \times 10^{3}\right.$ per $\left.\mathrm{ml}\right)$ of $P$. ramorum isolate \#264 in $0.5 \times$ Hoaglands solution. Plants were evaluated for stem lesion development at 7,14, and 21 days after inoculation as previously described.

Impact of delayed postinfection root stress on symptom development. To determine if a postinfection stress episode can stimulate symptom development, roots were immersed in zoospore suspensions for $24 \mathrm{~h}$ at low inoculum levels of $10^{2}$ or $10^{3}$ zoospores $/ \mathrm{ml}$. Plants were transferred to fresh $0.5 \times$ Hoaglands solution and incubated an additional $48 \mathrm{~h}$. Root stress was then imposed by transfer to $0.5 \times$ Hoaglands solution containing $0.2 \mathrm{M}$ $\mathrm{NaCl} / 0.02 \mathrm{M} \mathrm{CaCl}_{2}$. After $24 \mathrm{~h}$, the salt solution was removed, the roots flushed with DI water to remove salts, and the plants returned to $0.5 \times$ Hoaglands solution. As a positive control, a set of plants was inoculated by immersion of the roots in a concentrated zoospore suspension $\left(10^{5} / \mathrm{ml}\right)$, the same used to create the diluted inocula for the other treatments. All plants were returned to the growth chamber and evaluated for stem lesion development continuously over a 3 -week period. Two experiments were performed, and both $P$. ramorum isolates (\#264 and \#397) were used in each experiment. There was not a statistically significant difference between these isolates in lesion development, and thus the data are reported as composite results.

Experimental design and analysis. The general experimental design was complete randomized or randomized complete block, with four to seven individual plant replicates for each treatment. Experiments were performed at least twice or as indicated. The stem lesion data did not satisfy the ANOVA criterion for normality, and thus were analyzed by the Wilcoxon or 
Kruskal-Wallis rank sums tests. Lesion data expressed as a percentage of the stem length were transformed using the arcsine square root function. Level of significance was set at $\alpha=0.05$. Statistical analyses were performed using JMP software version 7.0 (SAS Institute, Cary, NC).

\section{RESULTS}

Hydroponic culture experiments. In initial experiments to establish the hydroponic system for root infection studies, both $P$. ramorum isolates readily infected Rhododendron and V. tinus roots. Root rot, stem lesions, and leaf wilting developed in all inoculated plants of both species. However, the rate at which symptoms developed was markedly different between stressed and nonstressed plants. Within 1 week after inoculation with $2 \times 10^{2}$ zoospores/ml, Rhododendron plants that had received a preinoculation salt stress had developed stem lesions sixfold greater $\left(\chi^{2}\right.$, 5.40; $P=0.02$ ) than those developing in the nonstressed plants (Fig. 1). Inoculated plants that experienced an episode of salt stress collapsed and became completely necrotic (Fig. 2A). As expected, disease development was faster at the higher inoculum levels $\left(2 \times 10^{3}\right.$ zoospores $\left./ \mathrm{ml}\right)$. Although during the course of the first week of observation the predisposing effect of salt stress was visually apparent, there was not a statistical difference between stressed and nonstressed plants exposed to the higher inoculum level at the two time points when lesions were meas- ured. As the infection advanced, leaves collapsed and became necrotic. Within 2 weeks, the stem surfaces of all inoculated plants were completely necrotic. Although healthy Rhododendron root systems are dark colored, the inoculated roots became noticeably darker in color over time and were necrotic at the termination of the experiment. Salt-stressed, but noninoculated controls were similar in appearance to the nonstressed, noninoculated controls, except for occasional marginal leaf necrosis in a few plants.

In contrast, stem lesions on inoculated Viburnum plants were not as obvious; however, roots were necrotic and the leaves permanently wilted (Fig. 2B). Plants that were not salt stressed but inoculated developed ramorum blight symptoms gradually, and the symptoms were less severe than in the salted/inoculated plants. By 2 weeks after inoculation, symptoms on the non-salt-stressed, inoculated plants were as severe as those on the saltstressed, inoculated plants at 1 week after inoculation. Microscopic examination of roots from both species revealed that their apices were covered with newly developed sporangia of $P$. ramorum. $P$. ramorum was isolated from all symptomatic tissuesroots, stems, and leaves - on PARP, affirming that $P$. ramorum zoospores can infect Rhododendron and $V$. tinus plants in this experimental regime and that the pathogen moves systemically into shoots and leaves.

Potted plant experiments. Results with potted plants were different from those

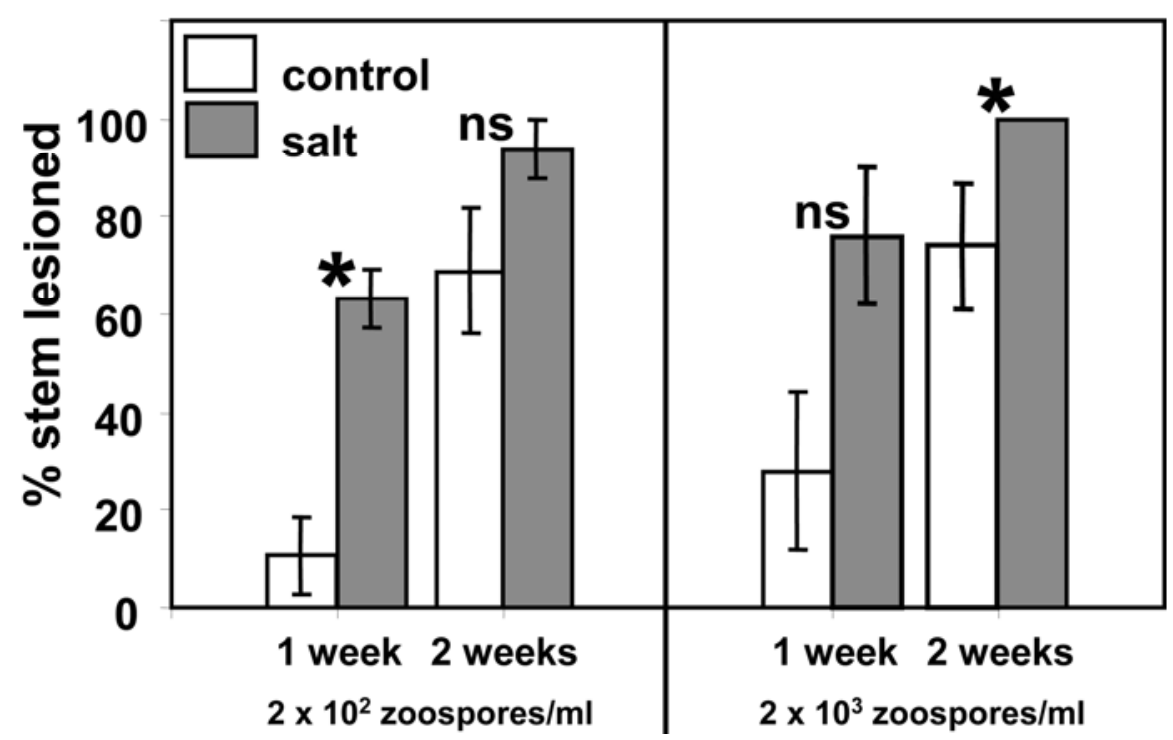

Fig. 1. Stem lesion development following root infection of nonstressed and salt-stressed Rhododendron hybrid Cunningham's White by Phytophthora ramorum. Experiments conducted in the hydroponic regime and the data are composite results with P. ramorum isolates \#264 and \#397 (isolates were not significantly different in virulence in this disease assay format in Rhododendron). Values are the percentage of the primary stem length that is necrotic, and each value is the mean and SE of four plants. Data were transformed by the arcsine square root function and analyzed by the Wilcoxon rank sums test. The average stem length of plants used in these experiments was $43 \pm 2 \mathrm{~mm} .2 \times 10^{2}$ zoospores/ml: 1 week, $*=$ column pair significantly different $\left(\chi^{2}, 5.40 ; P=0.02\right) ; 2$ weeks, ns $=$ column pair difference not significant $\left(\chi^{2}=2.19, P=0.14\right) .2 \times 10^{3}$ zoospores $/ \mathrm{ml}$ : 1 week, ns $=$ column pair difference not significant $\left(\chi^{2}=2.61, P=0.11\right) ; 2$ weeks, $*=$ column pair significantly different $\left(\chi^{2}=\right.$ 3.94, $P=0.05)$. with hydroponic plants in that the two $P$. ramorum isolates differentially affected the two host species. Isolate \#264 was highly virulent on potted Rhododendron plants, similar to hydroponic plants. Disease developed in salt-stressed roots with death of the plant occurring within 4 weeks. Nonstressed plants survived for 6 to 8 weeks before succumbing to disease, and symptom development in these plants was delayed by 1 to 2 weeks relative to the inoculated, salt-stressed plants. Isolate \#397 caused only limited stem lesions after 8 weeks on a few salt-treated Rhododendron plants, and only with the highest inoculum level tested $\left(2 \times 10^{4}\right.$ zoospores $\left./ \mathrm{ml}\right)$.

Potted Viburnum plants were relatively resistant to ramorum blight following root inoculation with either isolate under our experimental conditions. Disease had developed 8 weeks after inoculation only with isolate \#264 and only on one saltstressed plant. On this plant, roots had decayed, leaves were wilted, and the stem had a lesion that covered approximately $40 \%$ of the stem length.

Physiological assessment of the salt stress effect. To determine if a physiological impact of the salt treatment could be discerned in the potted plant format, we monitored changes in weight loss due to transpiration as a nondestructive whole plant measure of stress. In both Rhododendron and $V$. tinus, there was not a clear difference between salt-treated and control plants over the time course of observation in the incremental rate of transpirational water loss expressed as a percentage of the initial rate (data not shown). During the first $5 \mathrm{~h}$ of measurement, rates of transpirational weight loss in both salted and control plants fluctuated somewhat, but any differences were not significant. Between 9 and $24 \mathrm{~h}$, the transpiration rates leveled off to a similar level in both treatments. At the termination of the experiment $(24 \mathrm{~h})$, salt-stressed $V$. tinus and Rhododendron plants had similar rates of water loss, to about one-third of the initial rate. The general pattern is consistent with the plants displaying a circadian rhythm, where after about $6 \mathrm{~h}$ (late afternoon) the stomata are beginning to close. We did not take additional measurements beyond $24 \mathrm{~h}$ because of our primary interest in the response pattern prior to inoculation during the period of salt exposure and predisposition onset.

Exogenous ABA increases susceptibility of Rhododendron to $P$. ramorum. Both ABA and salt treatment of Rhododendron roots prior to inoculation significantly increased disease development relative to the nontreated control. At 7 days after inoculation, salt and ABA treatments were significantly different from the inoculated control (Kruskal-Wallis test, $\chi^{2}=15.5, P=$ 0.0004; Fig. 3). After this period, lesion size in the inoculated controls was similar to that in the other treatments. At 14 days 
after inoculation, lesion size was not significantly different between the ABAtreated and control plants $\left(\chi^{2}=0.77, P=\right.$ 0.38 ), and by 21 days after inoculation, disease severity was similar in all treatments. Lesion development following salt stress also was significantly different from the control at 14 days after inoculation $\left(\chi^{2}\right.$ $=9.77, P=0.002$ ).

Impact of delayed postinfection root stress on symptom development. To see if abiotic stress can stimulate root infections to give rise to systemic lesions, we exposed Rhododendron roots in the hydroponic regime to low inoculum levels of $P$. ramorum prior to salt treatment. Figure 4 illustrates that plants inoculated with $10^{2}$ zoospores $/ \mathrm{ml}$ and then $72 \mathrm{~h}$ later exposed to an episode of salt stress developed significantly larger stem lesions than the nonstressed controls when measured after 3 weeks (Wilcoxon rank sums test, $\chi^{2}=8.63$, $P=0.003$ ). In one experiment, inoculated but nonstressed plants at the lower inoculum level did not show any symptoms even at 3 weeks; however, in a second experiment, the nonstressed, inoculated plants displayed symptoms but less than those in the salt-stress, inoculated plants (Figure 4 represents the average of the two experiments). With $10^{3}$ zoospores $/ \mathrm{ml}$, the difference between control and salted plants was not significant at the 3 -week time point $\left(\chi^{2}\right.$ $=2.05, P=0.15)$. At the end of each experiment, the presence of $P$. ramorum was confirmed by isolation on PARP in all inoculated plants that were symptomatic and nonsymptomatic.

\section{DISCUSSION}

The importance of root infection by $P$. ramorum in the overall etiology and epidemiology of SOD and ramorum blight of various host species is unclear. Although roots were suspected as a likely infection court following isolation of the pathogen from naturally infected roots in some hosts, it was relatively recent that root infection was firmly established in controlled studies in Rhododendron and other species, suggesting a soil phase in the disease cycle $(24,35,40)$. $P$. ramorum can be found in the xylem underlying phloem lesions of tree hosts (8) and readily colonizes xylem elements following infection of roots of Rhododendron sp. (35). The pathogen appears to move rapidly via this pathway into shoots and leaves. The results of our experiments indicate that, similar to other Phytophthora species, P. ramorum has the capability to rapidly exploit roots following an episode of root stress. In addition, our results provide evidence that a postinfection stress episode can accelerate symptom expression, pointing to the potential role that abiotic stress could play in the activation of asymptomatic infections.

Whether abiotic root stress factors into the epidemiology and severity of SOD and ramorum blight under field conditions remains to be seen. Tree water potentials were not related to the incidence of SOD in woodlands (41). High temperatures and solar radiation (14) and, possibly, low leaf water potentials (16) are the principal ecophysiological factors that reduce oversummering survival of $P$. ramorum in Cali-
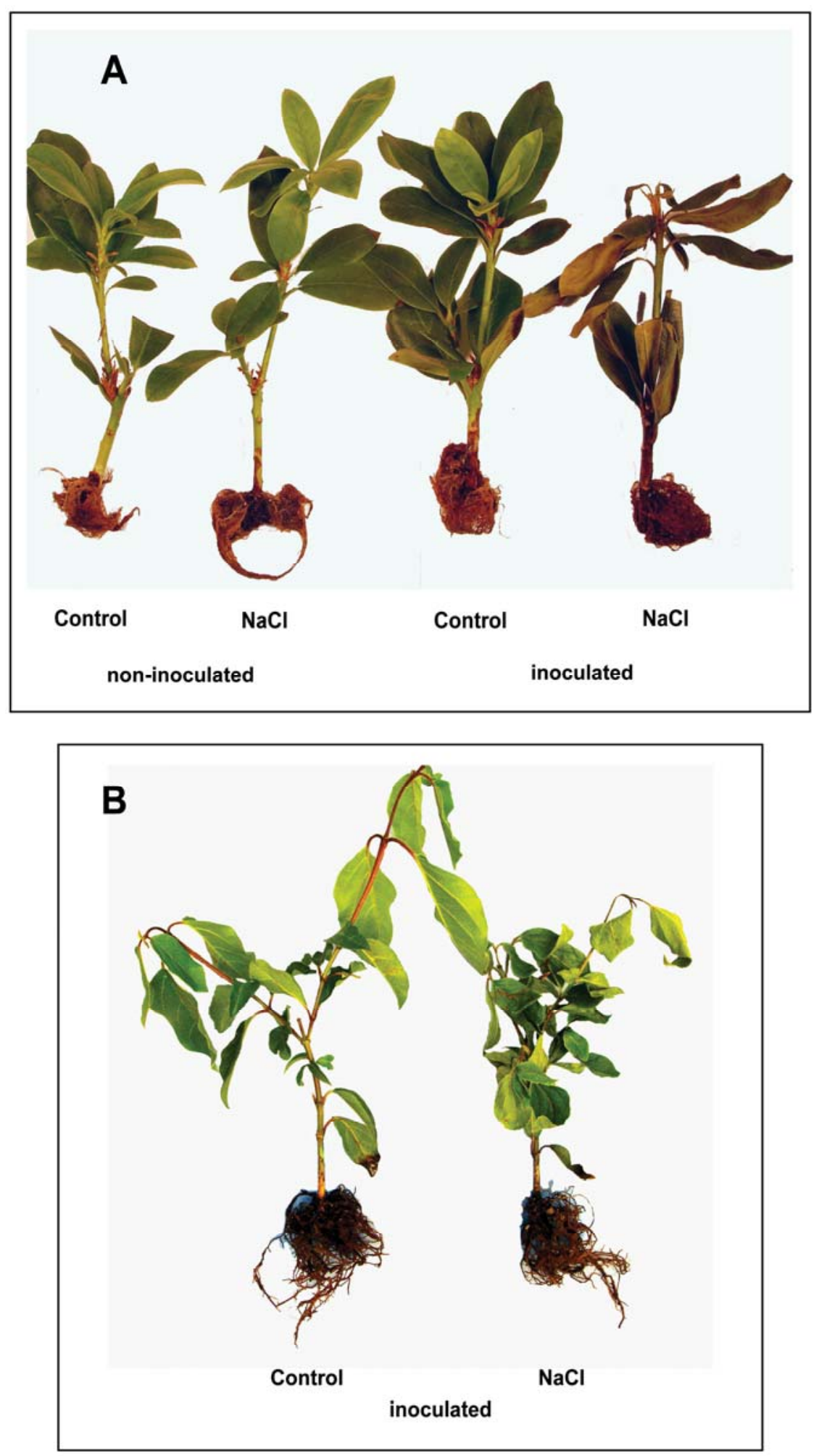

Fig. 2. A, The effect of a preinoculation episode of salt stress on disease development following inoculation of roots with Phytophthora ramorum in Rhododendron hybrid Cunningham's White. Plants were maintained in a hydroponic regime during the experiment and roots were inoculated with zoospores (2 $\times 10^{2} / \mathrm{ml}$ ) following a $16 \mathrm{~h}$ exposure to $\mathrm{NaCl}$. Photo taken 1 week after inoculation. B, Viburnum tinus $\mathrm{cv}$. Spring Bouquet plants showing the effect of $16 \mathrm{~h}$ salt stress prior to inoculation with zoospores $(2 \times$ $10^{3} / \mathrm{ml}$ ) of P. ramorum isolate \#397. Plants were maintained as in (A), 1 week after inoculation. Noninoculated control and salted plants (not shown) were healthy, similar in appearance to Rhododendron plants (A) with the corresponding treatments. 
fornia bay laurel leaves, a primary source of inoculum for SOD epidemics in mixed evergreen forests in California. The occurrence of $P$. ramorum in forests tends to be favored by closed canopies and cool, moist microclimates $(30,33)$. Thus, if water stress does occur, it likely inhibits disease development in these situations.

The difference in susceptibility of $V$. tinus plants between hydroponic and potted plant experiments and the difference in response of potted Rhododendron plants to the two isolates were unexpected. In the latter case, the isolate from California bay laurel (\#264) was highly virulent on potted plants, whereas only limited disease development was observed in these plants with the isolate from Ranunculus (\#397). There was no indication of a loss of virulence with the latter, as the potted plant experiments were conducted prior to or concurrently with the hydroponic culture experiments. The soil environment under our experimental conditions may be less con-

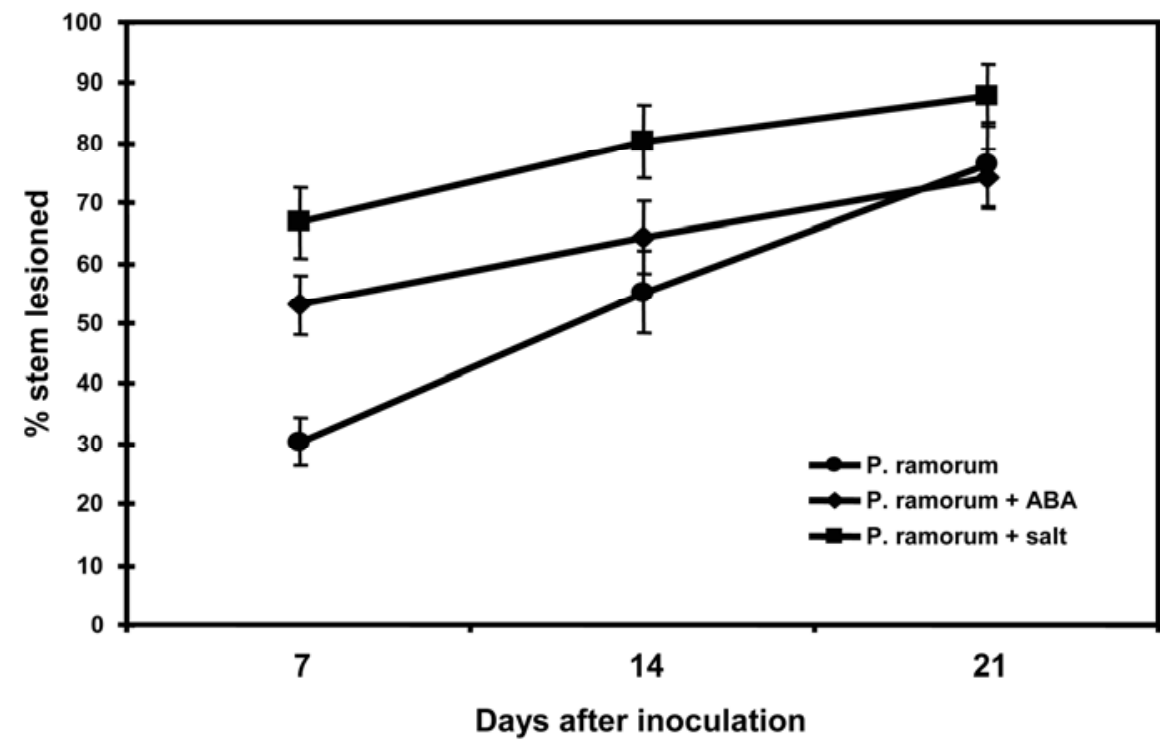

Fig. 3. Lesion development in nonstressed, salt-stressed, and abscisic acid (ABA)-treated ( $32 \mu \mathrm{M})$ Rhododendron hybrid Cunningham's White plants maintained in the hydroponic regime. Roots were inoculated $24 \mathrm{~h}$ after initiation of the first treatment with zoospores $\left(2 \times 10^{3} / \mathrm{ml}\right)$ of Phytophthora ramorum isolate \#397. Each value is the mean and SE of 18 (P. ramorum + ABA) or 20 (P. ramorum and $P$. ramorum + salt) plants from four experiments. See text for description of statistical analysis.

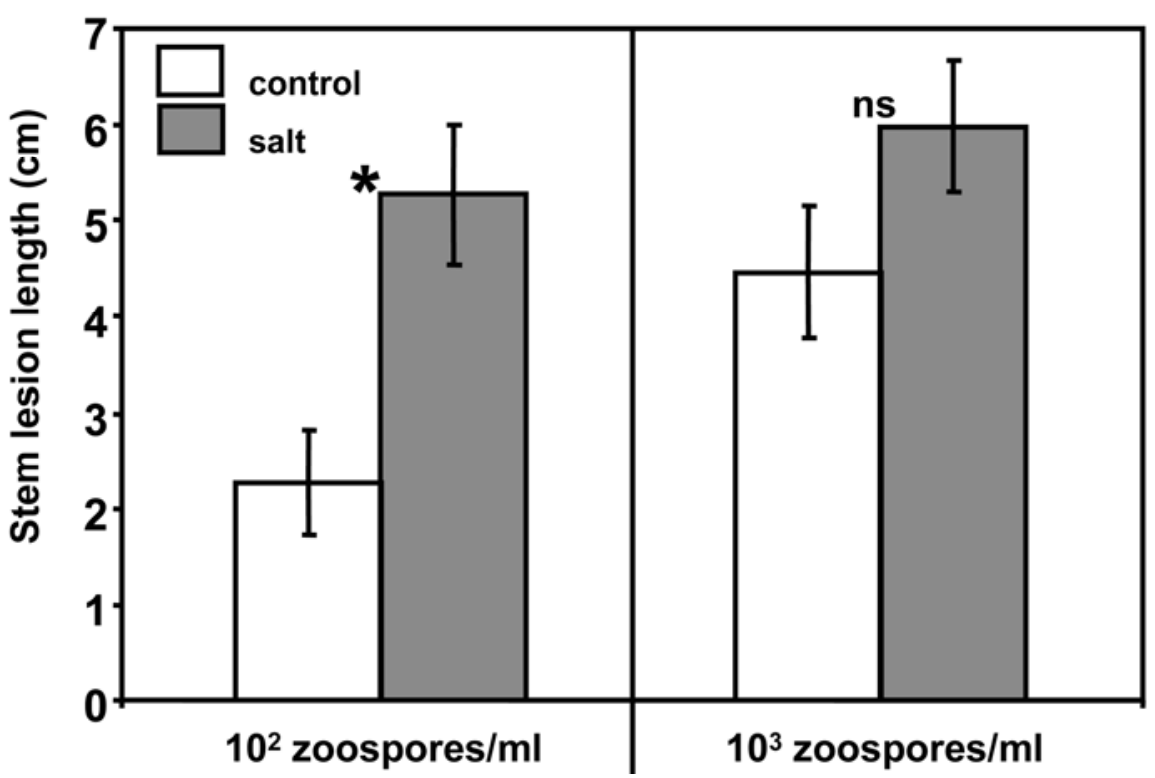

Fig. 4. The impact of delayed postinfection salt stress treatment on Phytophthora ramorum symptom development in Rhododendron in a hydroponic regime. Stem lesion data are the composite results for isolates \#264 and \#397 and are presented for two inoculum levels with symptoms evaluated 3 weeks after inoculation. Each value is the mean and SE of 22 plants from two experiments. * = column pair significantly different by Wilcoxon rank sums test, $\chi^{2}=8.63, P=0.003$. ns $=$ not significantly differently $\left(\chi^{2}=2.05, P=0.15\right)$.

ducive to infection than the hydroponic regime. We were unable to follow up on this aspect, so we are cautious about interpreting too much from these results. Nonetheless, it would be of interest to know the extent to which there are isolate differences in $P$. ramorum with respect to their occurrence and behavior in the soil environment and ability to initiate root infections.

The absence of a measurable effect of salt treatment on the transpiration rates in Rhododendron and Viburnum under our experimental conditions does not preclude a physiological impact on the roots and/or shoots. Leaves of Viburnum plants wilted within a few hours of exposure to salt, and rapidly recovered upon return to $0.5 \times$ Hoaglands. Rhododendron leaves did not wilt during the stress treatment, but a few plants displayed marginal leaf necrosis from salt. It is possible that under greenhouse conditions and higher light intensity, an effect of salt on transpiration would be apparent. However, the treatments were imposed under the fluorescent lights and laboratory humidity and temperature that we used for the stress induction phase throughout this study, conditions sufficient to predispose Rhododendron and V. tinus plants to infection by $P$. ramorum. Nonetheless, the physiological impact of the stress regime is transient and does not appear to perturb these species severely. In tomato, a more tractable model for the experimental study of predisposition than the ornamental species used in this study, plants begin to recover from a predisposed state about 4 to $6 \mathrm{~h}$ after removal of the roots from the salt-stress treatment (15).

Abiotic stresses such as those that predispose to Phytophthora root rots induce a degree of water stress in plants with a concomitant increase in levels of ABA in roots and shoots (42). A role for ABA in disease and predisposition is supported by studies with ABA-modified plants $(1,28)$. A preinoculation $\mathrm{ABA}$ treatment of roots in mesophytic species such as tomato mimics the predisposing effect of salt stress, and ABA-deficient mutants do not display a corresponding predisposition phenotype as ABA-normal plants $(5,6,15)$. Studies in potato $(21)$ and soybean $(10,29,31)$ demonstrated that ABA pretreatment of plants abrogated race-cultivar resistance to Phytophthora spp. and suppressed phytoalexin accumulation, and that ABA-synthesis inhibitors enhanced resistance. The results with $\mathrm{ABA}$ in Rhododendron reported in this study are concordant with findings in other systems. There has been resurgence in interest in ABA in disease processes in recent years, where it has been examined with different pathosystems incorporating ABA-mutants and abiotic stress in a few cases (23). In Arabidopsis, ABA treatment or drought stress induces susceptibility to Pseudomonas syringae pv. tomato (Pst DC3000) and to the downy mildew patho- 
gen Hyaloperonospora parasitica (32). Recently, an important study illustrated how effectors from Pst DC3000 co-opt ABA biosynthesis and signaling in Arabidopsis to cause disease (12). Salicylic acid-mediated responses associated with systemic acquired resistance to Pst appear to be a target for $\mathrm{ABA}$, whether it is applied exogenously or induced by $\mathrm{NaCl}$ stress $(43,47)$.

In our study, salinity (osmotic) stress was selected to examine predisposition to $P$. ramorum because this stress can be rapidly imposed and alleviated for experimental studies. Imposition of osmotic stress and inoculation were temporally separated to minimize any direct impact on zoospore behavior, thus focusing the predisposing effect of the stress as largely a result of altered host physiology. Other predisposing stressors such as water deficit, anoxia (waterlogging), and possibly cold stress, which also impact ABA-regulated processes, are candidates for future study as they are more likely to occur in nursery, shipment, and transplanting operations. It seems reasonable that activation of asymptomatic infections by episodic stress could contribute to the sudden onset of ramorum dieback and blight in some situations. In an open-air simulated container nursery system with contaminated overhead irrigation water, $P$. ramorum was frequently detected in root balls from asymptomatic Rhododendron and Viburnum plants (46). The complicating influence of predisposing stress on disease onset and severity is an additional consideration for risk assessment in nurseries impacted by $P$. ramorum.

\section{ACKNOWLEDGMENTS}

We thank Matt DiLeo, Dave Rizzo, Ken Shackel, and Lani Yakabe for advice and $P$. ramorum isolates, Neil Willets for statistical advice, and John Keller (Monrovia Nursery Co.) and Karen Suslow (Hines Nurseries, Inc.) for the generous donation of plants for these studies. This research was supported by a grant to RMB from the USDA Exotic/Invasive Pests and Diseases program and with funds from the University of California Agricultural Experiment Station.

\section{LITERATURE CITED}

1. Asselbergh, B., De Vieesschauwer, D., and Hofte, M. 2008. Global switches and finetuning - ABA modulates plant pathogen defense. Mol. Plant-Microbe Interact. 21:709719.

2. Bienapfl, J., Zanzot, J., Murphy, S., Garbelotto, M., and Rizzo, D. 2005. Isolation of a new lineage of Phytophthora ramorum from asymptomatic stems and roots of a commercial lot of rhododendron in California. (Abstr.) Phytopathology 95:S9-S10.

3. Blaker, N. S., and Macdonald, J. D. 1981. Predisposing effects of soil moisture extremes on the susceptibility of Rhododendron to Phytophthora root and crown rot. Phytopathology 71:831-834.

4. Blaker, N. S., and Macdonald, J. D. 1986. The role of salinity in the development of Phytophthora root rot of citrus. Phytopathology 76:970-975.

5. Bostock, R. M. 2005. Signal crosstalk and induced resistance: Straddling the line between cost and benefit. Annu. Rev. Phytopathol.
43:545-580.

6. Bostock, R. M., Macdonald, J. D., Duniway, J. M., and Stiles, J. 1990. Abscisic acid as a determinant of host susceptibility in salinity predisposition to Phytophthora root rot in chrysanthemum and tomato. (Abstr.) Phytopathology 80:1023.

7. Boyer, J. S. 1995. Biochemical and biophysical aspects of water deficits and the predisposition to disease. Annu. Rev. Phytopathol. 33:251-274.

8. Brown, A. V., and Brasier, C. M. 2007. Colonization of tree xylem by Phytophthora ramorum, P-kernoviae and other Phytophthora species. Plant Pathol. 56:227-241.

9. Buchanan, B. B., Gruissem, W., and Jones, R. L. 2000. Biochemistry and Molecular Biology of Plants. American Society of Plant Physiologists, Rockville, MD.

10. Cahill, D. M., and Ward, E. W. B. 1989. Rapid localized changes in abscisic acid concentrations in soybean in interactions with Phytophthora megasperma f. sp. glycinea or after treatment with elicitors. Physiol. Mol. Plant Pathol. 35:483-494.

11. Davidson, J. M., Werres, S., Garbelotto, M., Hansen, E. M., and Rizzo, D. M. 2003. Sudden oak death and associated diseases caused by Phytophthora ramorum. Plant Health Progress: doi:10.1094/PHP-2003-0707-01-DG.

12. de Torres-Zabala, M., Truman, W., Bennett, M. H., Lafforgue, G., Mansfield, J. W., Egea, P. R., Bogre, L., and Grant, M. 2007. Pseudomonas syringae pv. tomato hijacks the Arabidopsis abscisic acid signalling pathway to cause disease. EMBO J. 26:1434-1443.

13. Denman, S., Kirk, S. A., Orton, E., Webber, J. F., and Moralejo, E. 2007. Sporulation of Phytophthora ramorum and $P$. kernoviae on asymptomatic foliage. Sudden Oak Death Science Symposium III, Santa Rosa, CA.

14. DiLeo, M., Bostock, R., and Rizzo, D. 2007. Effects of environmental variables on the survival of Phytophthora ramorum in bay laurel leaves. Sudden Oak Death Science Symposium III, Santa Rosa, CA.

15. DiLeo, M. V. 2008. Ecophysiology of Phytophthora: Ecological and molecular interactions. Ph.D. diss. University of California, Davis.

16. DiLeo, M. V., Fichtner, E. J., Bostock, R. M., and Rizzo, D. M. 2006. Effects of water potential on the growth and survival of Phytophthora ramorum. (Abstr.) Phytopathology 96:S30.

17. Duniway, J. M. 1977. Predisposing effect of water stress on severity of Phytophthora root rot in safflower. Phytopathology 67:884-889.

18. Duniway, J. M. 1979. Water relations of water molds. Annu. Rev. Phytopathol. 17:431-460.

19. Duniway, J. M. 1983. Role of physical factors in the development of Phytophthora diseases. Pages 175-188 in: Phytophthora: Its Biology, Taxonomy, Ecology, and Pathology. D. C. Erwin, S. Bartnicki-Garcia, and P. H. Tsao, eds. American Phytopathological Society, St. Paul, MN.

20. Hansen, E. M. 2008. Alien forest pathogens: Phytophthora species are changing world forests. Boreal Environ. Res. 13:33-41.

21. Henfling, J., Bostock, R., and Kuc, J. 1980. Effect of abscisic acid on rishitin and lubimin accumulation and resistance to Phytophthora infestans and Cladosporium cucumerinum in potato tuber tissue slices. Phytopathology 70:1074-1078.

22. Jeffers, S. N., and Martin, S. B. 1986. Comparison of two media selective for Phytophthora and Pythium species. Plant Dis. 70:1038-1043.

23. Koga, H., Dohi, K., and Mori, M. 2004. Abscisic acid and low temperatures suppress the whole plant-specific resistance reaction of rice plants to the infection of Magnaporthe grisea.
Physiol. Mol. Plant Pathol. 65:3-9.

24. Lewis, C. D., Roth, M. L., Choquette, C. J., and Parke, J. L. 2004. Root infection of rhododendron by Phytophthora ramorum. (Abstr.) Phytopathology 94:S60.

25. Linderman, R. G., and Davis, E. A. 2008. Evaluation of chemical agents for the control of Phytophthora ramorum and other species of Phytophthora on nursery crops. Plant Health Progress DOI:101094/PHP-2008-0211-01-RS.

26. Macdonald, J. D. 1982. Effect of salinity stress on the development of Phytophthora root rot of chrysanthemum. Phytopathology 72:214-219.

27. Macdonald, J. D. 1984. Salinity effects on the susceptibility of chrysanthemum roots to Phytophthora cryptogea. Phytopathology 74:621624.

28. Mauch-Mani, B., and Mauch, F. 2005. The role of abscisic acid in plant-pathogen interactions. Curr. Opin. Plant Biol. 8:409-414.

29. McDonald, K. L., and Cahill, D. M. 1999. Influence of abscisic acid and the abscisic acid biosynthesis inhibitor, norflurazon, on interactions between Phytophthora sojae and soybean (Glycine max). Eur. J. Plant Pathol. 105:651658.

30. Meentemeyer, R. K., Rank, N. E., Anacker, B. L., Rizzo, D. M., and Cushman, J. H. 2008. Influence of land-cover change on the spread of an invasive forest pathogen. Ecol. Appl. 18:159-171.

31. Mohr, P. G., and Cahill, D. M. 2001. Relative roles of glyceollin, lignin and the hypersensitive response and the influence of $\mathrm{ABA}$ in compatible and incompatible interactions of soybeans with Phytophthora sojae. Physiol. Mol. Plant Pathol. 58:31-41.

32. Mohr, P. G., and Cahill, D. M. 2003. Abscisic acid influences the susceptibility of Arabidopsis thaliana to Pseudomonas syringae pv. to mato and Peronospora parasitica. Funct. Plant Biol. 30:461-469.

33. Murphy, S. K., Wickland, A. C., Lynch, S. C Jensen, C. E., Maloney, P. E., and Rizzo, D. M 2008. Distribution of Phytophthora ramorum, $P$. nemorosa, and P. pseudosyringae in native coastal California forest communities. Proc. Sudden Oak Death 3rd Sci. Sympos. U.S. Dep. Agric. For. Serv. Pacific Southwest Res. Stn. Santa Rosa, CA.

34. Parke, J. L., Bienapfl, J., Oh, E., Rizzo, D., Hansen, E., Buckles, G., Lee, C., and Valachovic, Y. 2006. Natural infection of tanoak seedling roots by Phytophthora ramorum. (Abstr.) Phytopathology 96:S90.

35. Parke, J. L., and Lewis, C. 2007. Root and stem infection of rhododendron from potting medium infested with Phytophthora ramorum. Plant Dis. 91:1265-1270.

36. Rizzo, D. M., and Garbelotto, M. 2003. Sudden oak death: Endangering California and Oregon forest ecosystems. Front. Ecol. Environ. 1:197-204.

37. Rizzo, D. M., Garbelotto, M., Davidson, J. M. Slaughter, G. W., and Koike, S. T. 2002. Phytophthora ramorum as the cause of extensive mortality of Quercus spp. and Lithocarpus densiflorus in California. Plant Dis. 86:205214.

38. Rizzo, D. M., Garbelotto, M., and Hansen, E. A. 2005. Phytophthora ramorum: Integrative research and management of an emerging pathogen in California and Oregon forests. Annu. Rev. Phytopathol. 43:309-335.

39. Roubtsova, T. V., and Bostock, R. M. 2008 Impact of episodic root stress on the susceptibility of Rhododendron sp. and Viburnum tinus to Phytophthora ramorum. (Abstr.) Phytopathology 98:S136.

40. Shishkoff, N. 2007. Persistence of Phytophthora ramorum in soil mix and roots of nursery ornamentals. Plant Dis. 91:1245-1249.

41. Swiecki, T. J., and Bernhardt, E. 2002. Evaluation of stem water potential and other tree and 
stand variables as risk factors for Phytophthora ramorum canker development in coast live oak. Sympos. Calif. Oak Woodlands, 5th. U.S. Dep. Agric. For. Serv., Gen. Tech. PSW-GTR184.

42. Taiz, L., and Zeiger, E. 2006. Plant Physiology. 4th ed. Sinauer Associates, Sunderland, MA.

43. Thaler, J. S., and Bostock, R. M. 2004. Interactions between abscisic-acid-mediated responses and plant resistance to pathogens and insects. Ecology 85:48-58.

44. Tjosvold, S. A., Koike, S. T., and Chambers,
D. L. 2008. Evaluation of fungicides for the control of Phytophthora ramorum infecting Rhododendron, Camellia, Pieris, and Viburnum. Plant Health Progress DOI:101094/PHP2008-0208-01-RS.

45. Werres, S., Marwitz, R., Veld, W., De Cock, A., Bonants, P. J. M., De Weerdt, M., Themann, K., Ilieva, E., and Baayen, R. P. 2001. Phytophthora ramorum sp nov., a new pathogen on Rhododendron and Viburnum. Mycol. Res. 105:1155-1165.

46. Werres, S., Wagner, S., Brand, T., Kaminski,
K., and Seipp, D. 2007. Survival of Phytophthora ramorum in recirculating irrigation water and subsequent infection of Rhododendron and Viburnum. Plant Dis. 91:1034-1044.

47. Yasuda, M., Ishikawa, A., Jikumaru, Y., Seki, M., Umezawa, T., Asami, T., MaruyamaNakashita, A., Kudo, T., Shinozaki, K., Yoshida, S., and Nakashita, H. 2008. Antagonistic interaction between systemic acquired resistance and the abscisic acid-mediated abiotic stress response in Arabidopsis. Plant Cell 20:1678-1692. 